\author{
Research Article \\ www.ijrap.net
}

\title{
CURCUMIN AND METRONIDAZOLE IN PERIODONTAL THERAPY
}

\author{
Merline K. Varghese ${ }^{1 *}$, Nagarathna D. ${ }^{2}$, Litty Scariya ${ }^{1}$
}

${ }^{1}$ PG student, Department of Periodontics, A. J Institute of Dental Sciences, Mangalore, Karnataka, India

${ }^{2}$ Professor, Department of Periodontics, A. J Institute of Dental Sciences, Mangalore, Karnataka, India

Received on: 03/09/14 Revised on: 10/10/14 Accepted on: 23/10/14

*Corresponding author

Dr. Merline K. Varghese, Final year Postgraduate student, Department of Periodontics, NH-66, A. J. Institute of Dental Sciences, Kuntikana, Mangalore-575004 Karnataka, India E-mail: merlinevarghese89@gmail.com

DOI: 10.7897/2277-4343.056138

\begin{abstract}
The goal of periodontal therapy is to prevent, arrest, control or eliminate periodontitis. It has been reported that scaling and root planning, when combined with local delivery system such as sub gingival medicament reduces microbes and improves clinical parameters better than scaling and root planning alone. Therefore the aim of the present study was to compare the clinical efficacy between two medicaments, delivered in gel form, one containing metronidazole and the other containing curcumin, as an adjunct to mechanotherapy. Fifteen subjects were selected, based on the inclusion and exclusion criteria of both sexes, in a split mouth design. Selected sites were randomly divided into two groups (group A -metronidazole whereas group B - curcumin) and the following clinical parameters such as gingival index (GI), modified sulcular bleeding index (mSBI), probing pocket depth (PPD) were recorded and assessed on day 0 and $30^{\text {th }}$ days. When compared with metronidazole, a significant decrease in all clinical parameters was seen using curcumin. This study revealed that the experimental local drug i.e. curcumin used along with scaling and root planning is effective in reducing gingival inflammation and reducing pocket depth.
\end{abstract}

Keywords: Metronidazole gel, Curcumin gel and Periodontitis

\section{INTRODUCTION}

A periodontal disease is a general term which encompasses several pathological conditions affecting the tooth supporting structures. ${ }^{1}$ Dental plaque has been proved by extensive research of Harold Loe (1965) to be a paramount factor in initiation and progression of gingival and periodontal diseases. ${ }^{2,3}$ Due to which, much of the research should be directed towards a more effective and economic means of plaque control that can prevent further disease progression. Treatment of periodontal disease is routinely based on mechanical debridement of the tooth surface and appropriate and meticulous maintenance of oral hygiene. However, comprehensive mechanical debridement of sites with deep periodontal pockets is difficult to accomplish. ${ }^{4,5}$ As an adjunctive approach, systemic or local administration of antibiotics is done because of the microbial aetiology of periodontitis. Various disadvantages of the systemic antibiotic therapy, like hypersensitivity reaction, organ toxicity and development of resistant bacteria, coupled with its requirement of higher dosage to attain required GCF concentration at the target site, led to the use of local drug-delivery system. ${ }^{4,6}$ Among the antimicrobials used for the treatment of periodontitis, metronidazole is particularly suitable, due to its restricted spectrum of activity against obligate anaerobes ${ }^{7,8}$ and its limited side effects, compared to those of tetracyclines, i.e., selection of multi resistant bacteria ${ }^{7,9}$ and perturbation of the normal micro biota of the body. Hence, a need was felt of an alternative medicine that could provide a product already enmeshed within the traditional Indian setup and is also safe and economical. Turmeric, more commonly known as 'Haldi', is a rhizome of Curcuma longa, and may be a more acceptable and viable option for the common man. It has proven properties like antiinflammatory, ${ }^{10,11}$ antioxidant ${ }^{12-14}$ and antimicrobial ${ }^{15,16}$ along with its hepatoprotective, ${ }^{17-22}$ immunostimulant, antiseptic, anti mutagenic properties. ${ }^{23-30}$ Due to these reasons, it was felt that promotion of turmeric in dental terrain may prove beneficial. ${ }^{2,31}$ Hence; this present study was to compare the clinical efficacy between two local drug delivery systems, delivered in gel form, one containing metronidazole and the other containing curcumin, as an adjunct to mechanotherapy.

\section{MATERIALS AND METHODS}

Commercially available Metronidazole gel (metrogyl) each gram contains $10 \mathrm{mg}$ metronidazole and Curcumin gel (curenext) - each gram contains $10 \mathrm{mg}$ Curcuma longa extract.

\section{Methods of randomisation of subjects}

This study was conducted in a split mouth design on 15 subjects in each group of both sexes. Subjects were randomly selected from those attending the Department of Periodontics, A. J. Institute of Dental Sciences, Mangalore, India. Subjects were selected on the basis of the following criteria by examining the periodontium.

\section{Inclusion criteria}

Patients having at least 3 sites with probing pocket depth $\geq 4 \mathrm{~mm}$ and $\leq 6 \mathrm{~mm}$; patients with moderately or severely inflamed gingiva that bleeds on probing; patients with at least 20 remaining teeth were considered.

\section{Exclusion criteria}

Subjects wearing removable partial dentures and undergoing orthodontic therapy; sites adjacent to recent extraction sites; teeth showing endoperio lesions, restorations and other plaque retentive factors; pregnant and lactating females; subjects taking anti-inflammatory drugs, antibiotics, immunosuppressant or oral 
contraceptives since last 6 months would not be taken up for study; subjects sensitive and allergic to any medicine; tobacco users; medically compromised patients and patients having debilitating diseases.

\section{Approval by ethical committee}

The study protocol was reviewed by the 'Ethical Committee' of A. J. Institute of Dental Sciences.

\section{Study protocol}

The relevant data were recorded in a special proforma sheet. Clinical examination was done in a dental chair, under standard conditions of light, using a mouth mirror, explorer, William's graduated periodontal probe and tweezers; and assessment of clinical parameters was carried out. Selected sites were randomly divided into two groups which were treated using split-mouth design and clinical parameters were recorded. Group A- 15 subjects were treated with scaling and root planning followed by placement of experimental material (metronidazole). Group B - 15 subjects were treated with scaling and root planning followed by placement of experimental material (curcumin).

\section{Recording of clinical parameters}

The following clinical parameters were recorded for all subjects at baseline and at $30^{\text {th }}$ day: -Modified sulcular bleeding index (mSBI - Mombelli et al 1987), gingival index (GI - Loe and Silness 1963) was scored, periodontal pocket (probing pocket depth-PPD) was measured using Williams Periodontal Probe.

\section{Mode of Local Drug Delivery}

On completion of scaling and root planning, each group was isolated with cotton rolls to prevent contamination from saliva. A $2 \mathrm{ml}$ disposable syringe equipped with a blunted 25 gauge needle, which was bent along its shank at an approximately $130^{\circ}$ were used. The pocket opening was covered with Coe-pack to retain the material in the pocket as well as to prevent ingress of oral fluids. Subjects were recalled after 7 days for removal of the periodontal dressing. Recall visits were again scheduled after 30 days of placement of experimental drug for measuring the clinical parameters.

\section{Data Analysis}

The data was tabulated in Microsoft excel and analysed using SPSS version 16. Comparison of the baseline and the 30 day values in each group separately were analysed using Paired t Test. (Intra group). Comparison of the differences from baseline to $30^{\text {th }}$ day between the two groups was analysed using Unpaired t Test. (Inter group). The level of significant was set to $\mathrm{p}<0.05$.

\section{Comparison of the baseline and the 30 day values in each group separately: paired t test (graph 1 and 2)}

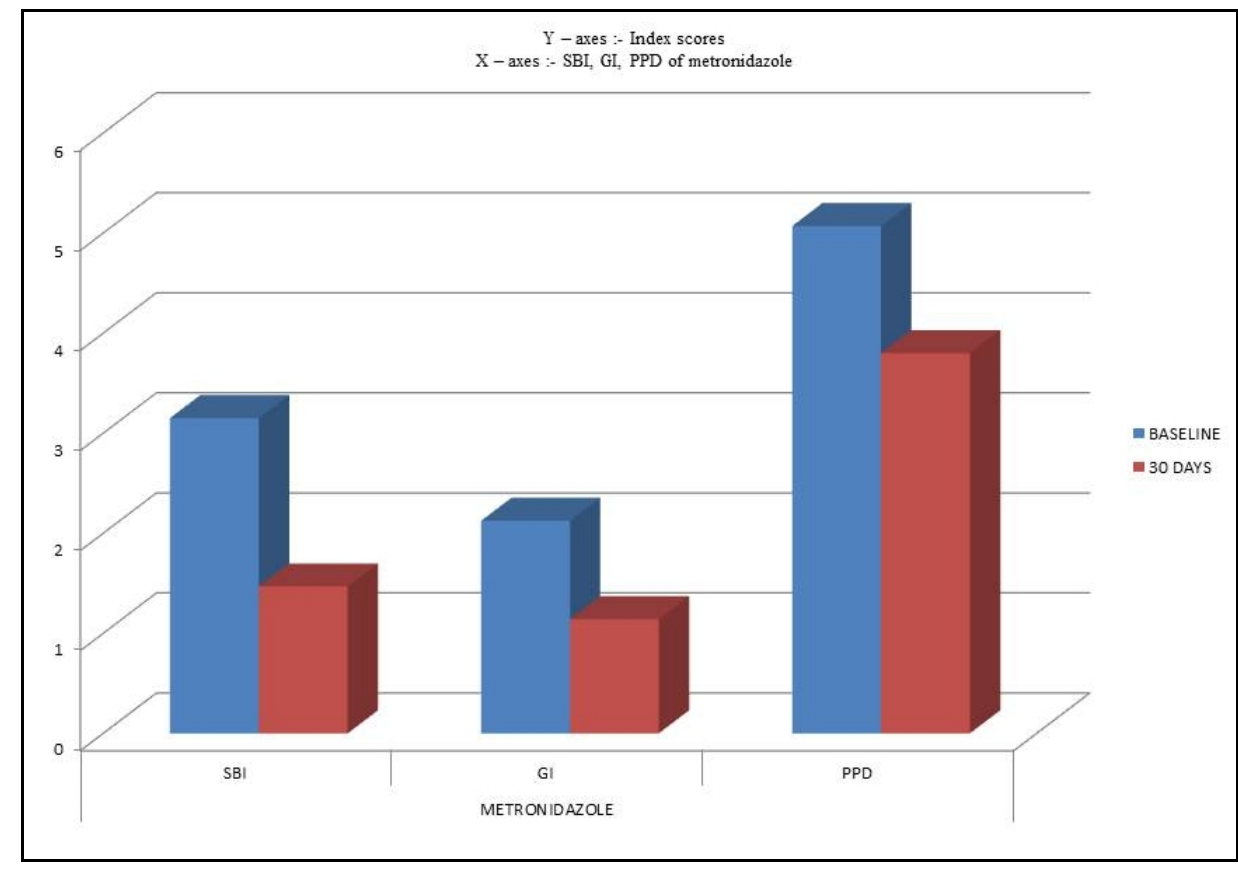

Graph 1: Metronidazole group

Graph 1 showed that in group-A (metronidazole), there was significant reduction in all clinical parameters i.e., sulcular bleeding index, gingival index and pocket probing depth from the baseline to $30^{\text {th }}$ day. 


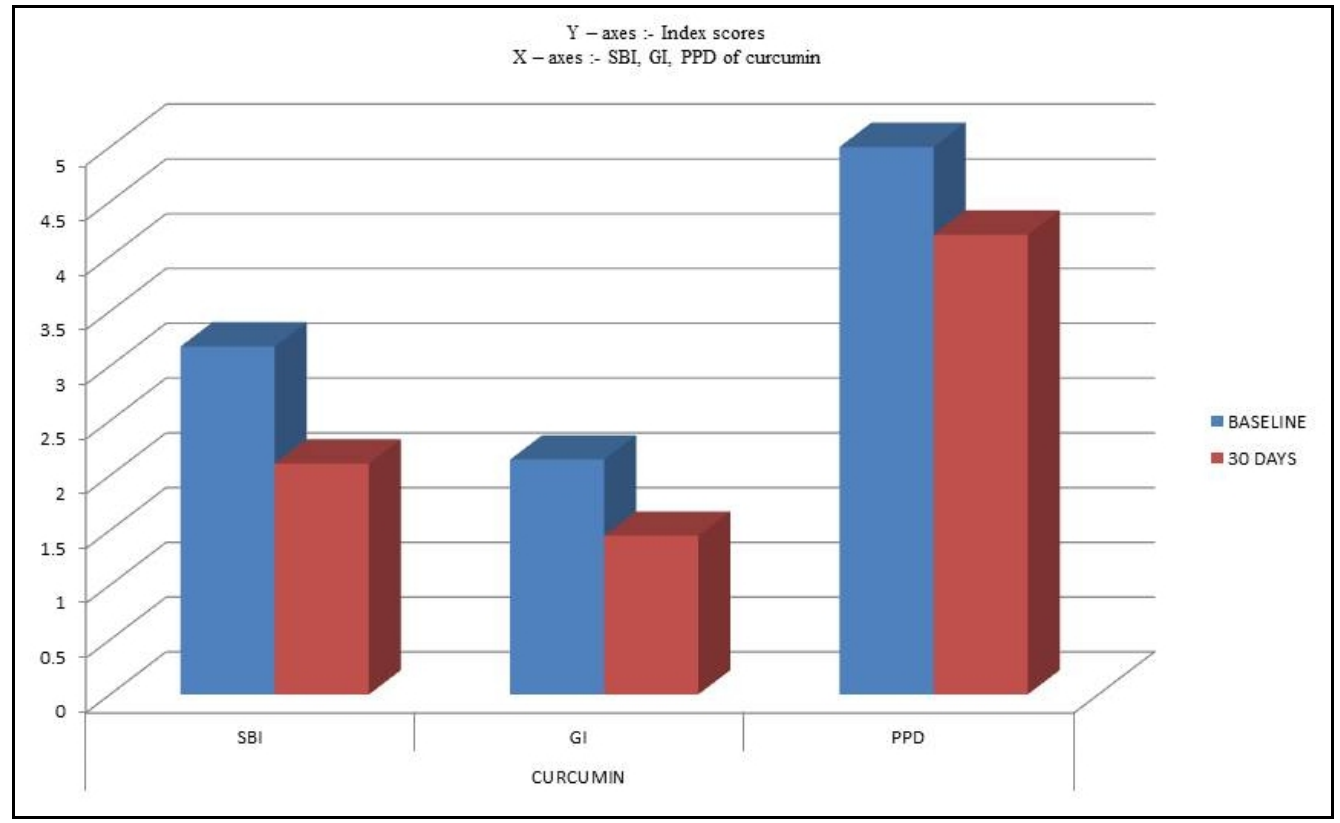

Graph 2: Curcumin group

Graph 2 showed that in group-B (curcumin), there was significant reduction in all clinical parameters i.e., SBI, GI and PPD from the baseline to $30^{\text {th }}$ day. However, greater reductions were observed in group - B in comparison with group A as seen in graph 3 .

\section{Graph 3: Comparison of the differences between the two groups from baseline to $30^{\text {th }}$ day: Unpaired $t$ test}

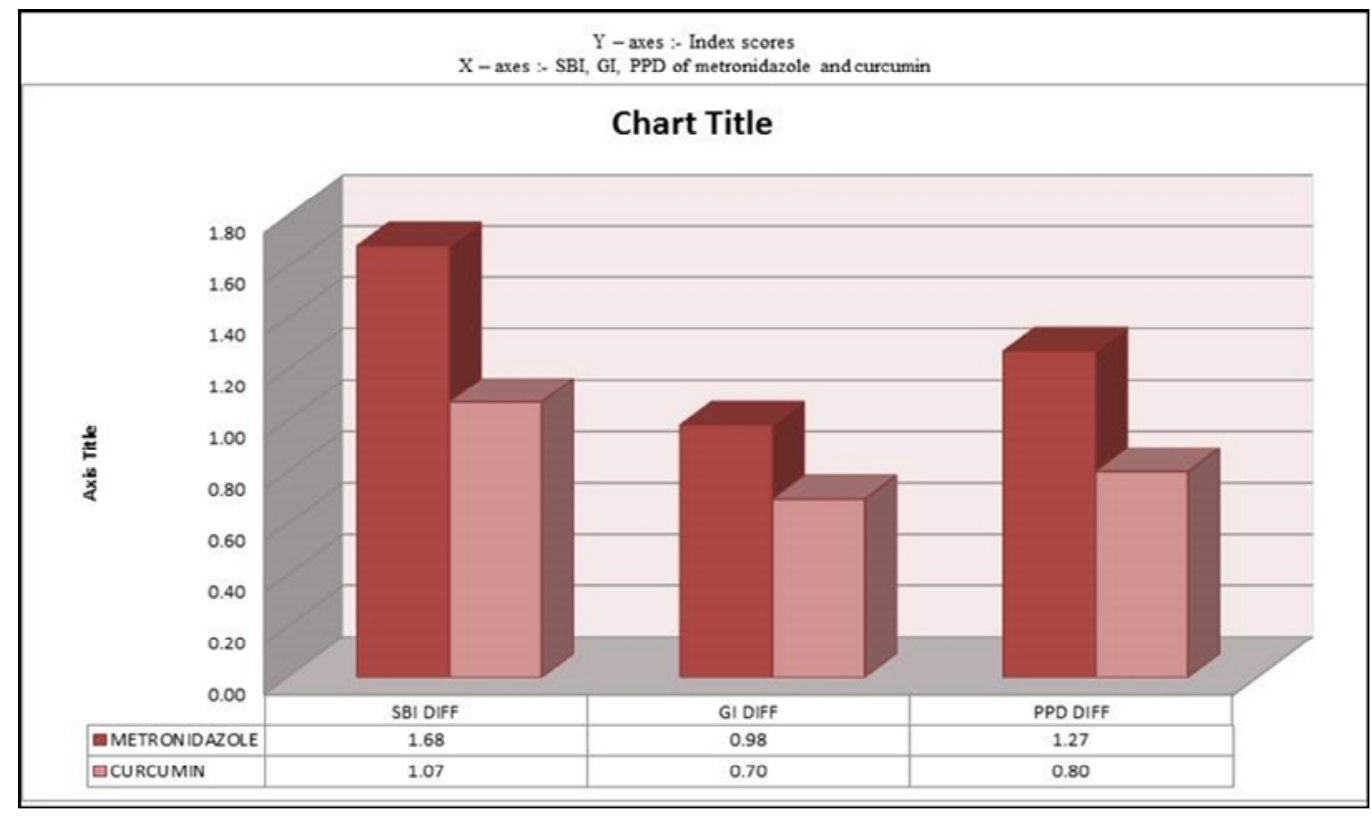

Graph 3: Metronidazole and Curcumin comparison from baseline to $30^{\text {th }}$ day

Graph 3 reveals that there is significant reduction in group B (curcumin) in all clinical parameters when compared to group A (metronidazole). 


\section{DISCUSSION}

Advances in understanding the aetiology and pathogenesis have led to the development and subsequent acceptance of the use of pharmacological agents in the management of periodontal diseases. Local drug delivery systems have the ability to deliver the antibiotic to the target sites, achieve a sufficient concentration, and last for a sufficient duration to be effective. ${ }^{32}$ Hence this present study was to compare the clinical efficacy between two local drug delivery systems, delivered in gel form, one containing metronidazole and other containing curcumin. Among the antibiotics that have been considered for periodontal treatment, Metronidazole has often been chosen because of its selective efficacy against obligate anaerobes. It acts by inhibiting DNA synthesis. It is known to convert into a reactive reduced form and affects specifically anaerobic rods and spirochetes in sub gingival microflora. ${ }^{1}$ In this study, group A (metronidazole), gingival scores reduction was observed and it found to be reduced from 2.123733 to 1.1416 and there was significant reduction in pocket probing depth as well. These results were attributed to its following antibacterial properties through the following mechanism this reduction in inflammation and presence of healing in the connective tissue subjacent to the junctional epithelium is the primary reason for reducing the depth of periodontal probe penetration after treatment. Metronidazole follows first order kinetics i.e., gel provides increased drug concentration for $24 \mathrm{~h}$ after which it subsequently decreases rapidly at a rate directly proportional to their pocket concentration. ${ }^{33}$ Whereas in curcumin group, gingival scores reduction was observed from 2.145267 to $1.4496(\mathrm{p}<0.001)$. These results were attributed to its following anti-inflammatory and wound healing properties it reduces the inflammatory mediators generated via arachiodonic acid pathway and causes shrinkage by reducing inflammatory oedema and vascular engorgement of connective tissue. It also promotes migration of various cells including fibroblasts in wound bed and thus results in reduction of vascularization by bringing about fibrosis of connective tissue. It also promotes migration of epithelial cells to wounded sites by promoting localization of TGF- $\beta 1$ thus helping in reepithelization. ${ }^{434}$ Trend for reduction in pocket depth by curcumin can be due to the ability of enhancing regeneration after traumatic injury as demonstrated in this present study and which is in accordance with the study conducted by sidhu et al (in an in vivo experiment on rats and guinea pigs $)^{35}$ as well as in a study conducted by gopinath et al. ${ }^{36}$ However based on the clinical parameters, on comparison between both the groups, curcumin proved to be statistically better than metronidazole. It is clear from the above results that the experimental local drug i.e. curcumin used along with scaling and root planning is effective in reducing gingival inflammation and reducing pocket depth. It also controls the localized infection and prevents new lesion formation. The local drug-delivery system used in the present study is simple and easy to use. Its suitability for use with a syringe allows easy insertion into the pocket. It is also biologically accepted without any side effects.

\section{Limitations}

The limitation of this study was that microbial analysis was not carried out and long term study should be carried out to further strengthen these claims.

\section{CONCLUSION}

Inspite of all these limitations, curcumin showed better results in all clinical parameters. In this investigation, we introduced curcumin, as a local drug delivery to reduce inflammatory gingival signs and promote better healing with reduced pocket depth and demonstrated its superior efficacy when compared to widely used medicament i.e. Metronidazole.

\section{REFERENCES}

1. Dr Vidyadodwad, Dr Shubhravaish, Dr Aakritimahajan, Dr Mehakchhokra. Local drug delivery in periodontics: A strategic intervention. Int J Pharm Pharm Sci 2012; 4(4): 30-34.

2. PF Waghmare, AU Chaudhari, VM Karhadkar, AS Jamkhande. Comparative evaluation of turmeric and chlorhexidinegluconate mouthwash in prevention of plaque formation and gingivitis: A clinical and microbiological study. J Contemp Dent Pract 2011; 12(4): 221-224. http://dx.doi.org/10.5005/jp-journals-10024-1038

3. Fine HD. Chemical agents to prevent and regulate plaque development. Perio 2000. 1995; 8: 87-107. http://dx.doi.org/ 10.1111/j.1600-0757.1995.tb00047.x

4. Roobal Behal, Amita M Mali, Suhit S Gilda and Anant R Paradkar. Evaluation of local drug-delivery system containing $2 \%$ whole turmeric gel used as an adjunct to scaling and root planning in chronic periodontitis: A clinical and microbiological study. J Indian Soc Periodontol 2011; 15(1): 35-38. http://dx.doi.org/10.4103/0972124X.82264

5. Cobb CM. Nonsurgical pocket therapy: Mechanical. Ann Periodontol 1996; 1: 443-90. http://dx.doi.org/10.1902/ annals. 1996.1.1.443

6. Greenstein G. Local drug delivery in the treatment of periodontal diseases: Assessing the clinical significance of the results. J Periodontol 2006; 77: 565-78. http://dx.doi.org/10.1902 /jop.2006.050140

7. Sandra Sato, Maria Jose Vieira Fonseca, Jose Roberto Jabor, Vinicius Pedrazzi. Metronidazole-containing gel for the treatment of periodontitis: An in vivo evaluation. Braz Oral Res 2008; 22(2): 145-50. http://dx.doi.org/10.1590/S1806-83242008000200009

8. Mitchell DA. Metronidazole: its use in clinical dentistry. J Clin Periodontol 1984; 11(3): 145-58. http://dx.doi.org/10.1111/j.1600051X.1984.tb01318.X

9. Slots J. Selection of antimicrobial agents in periodontal therapy. J Periodontal Res 2002; 37(5): 389-98. http://dx.doi.org/10.1034 /j.1600-0765.2002.00004.x

10. Ammon HP, Safayhi H, Mack T, Sabieraj J. Mechanism of antiinflammatory actions of curcumin and boswellic acids. J Ethnopharmacol 1993; 38: 113-9. http://dx.doi.org/10.1016/03788741(93)90005-P

11. Mukhopadhyay A, Basu N, Ghatak N. Anti-inflammatory and irritant activities of curcumin analogues in rats. Agents Actions 1982; 12: 508-15. http://dx.doi.org/10.1007/BF01965935

12. Ramirez Bosc $\alpha$ A, Soler A, Gutierrez MA. Antioxidant curcuma extracts decrease the blood lipid peroxide levels of human subjects. Age 1995; 18: 167-9. http://dx.doi.org/10.1007/BF02432631

13. Toda S, Miyase $\mathrm{T}$, Arich $\mathrm{H}$. Natural antioxidants. Anti oxidative compounds isolated from rhizome of Curcuma longa L. Chem Pharmacol Bul 1985; 33: 1725-28. http://dx.doi.org/10.1248 /cpb.33.1725

14. Mortellini R, Foresti R, Bassi R, Green CJ. Curcumin, an antioxidant and anti-inflammatory agent, induces heme oxygenase-1 and protects endothelial cells against oxidative stress. Free Radic Biol Med 2000; 28: 1303-12. http://dx.doi.org/10.1016/S08915849(00)00294-X

15. Apisariyakul A, Vanittanakom N, Buddhasukh D. Antifungal activity of turmeric oil extracted from Curcuma longa (Zingiberaceae). J Ethnopharmacol 1995; 49: 163-9. http://dx. doi.org/10.1016/0378-8741(95)01320-2

16. Rasmussen HB, Christensen SB, Kvist LP, Karazami A. A simple and efficient separation of the curcumins, the anti protozoal 
constituents of Curcuma longa. Planta Med 2000; 66: 396-8. http://dx.doi.org/10.1055/s-2000-8533

17. Deshpande UR, Gadre SG, Raste AS. Protective effect of turmeric (Curcuma longa L.) extract on carbon tetrachloride-induced liver damage in rats. Indian J Exp Biol 1998; 36: 573-7.

18. Park EJ, Jeon CH, Ko G, Kim J, Sohn DH. Protective effect of curcumin in rat liver injury induced by carbon tetrachloride. J Pharm Pharmacol 2000; 52: 437-40. http://dx.doi.org/10.1211/ 0022357001774048

19. Kiso Y, Suzuki Y, Watanabe N, Oshima Y, Hikino H. Anti hepatotoxic principles of Curcuma longa rhizomes. Planta Med 1983; 49: 185-87. http://dx.doi.org/10.1055/s-2007-969845

20. Donatus IA, Sardjoko, Vermeulen NP. Cytotoxic and cytoprotective activities of curcumin. Effects on paracetamol-induced cytotoxicity, lipid peroxidation and glutathione depletion in rat hepatocytes. Biochem Pharmacol 1990; 39: 1869-75. http://dx.doi.org/10.1016 /0006-2952(90)90603-I

21. Soni KB, Rajan A, Kuttan R. Reversal of aflatoxin induced liver damage by turmeric and curcumin. Cancer Lett 1992; 66: 115-21. http://dx.doi.org/10.1016/0304-3835(92)90223-I

22. Ramprasad C, Sirsi M. Curcuma longa and bile secretion.Quantitative changes in the bile constituents induced by sodium curcuminate. J Sci Ind Res 1957; 16: 108-10.

23. Mehta K, Pantazis P, Mc Queen T, Aggarwal BB. Anti proliferative effect of curcumin (diferuloylmethane) against human breast tumor cell line. Anticancer Drugs 1997; 8: 470-81. http://dx.doi.org/ 10.1097/00001813-199706000-00010

24. Menon LG, Kuttan R, Kuttan G. Anti-metastatic activity of curcumin and catechin. Cancer Lett 1991; 141: 159-65. http://dx .doi.org/10.1016/S0304-3835(99)00098-1

25. Kawamori T, Lubet R, Steele VE. Chemopreventative effect of curcumin, a naturally occurring anti-inflammatory agent, during the promotion/progression stages of colon cancer. Cancer Res 1999; 59: 597-01.

26. Thaloor D, Singh AK, Sidhu GS, Prasad PV, Kleinman HK, Maheshwari RK. Inhibition of angiogenic differentiation of human umbilical vein endothelial cells by curcumin. Cell Growth Differ 1998; 9 (4): 305-12.

27. Limtrakul P, Lipigorngoson S, Namwong O, Apisariyakul A, Dunn FW. Inhibitory effect of dietary curcumin on skin carcinogenesis in mice. Cancer Lett 1997; 116 (2): 197-203. http://dx.doi.org/ 10.1016/S0304-3835(97)00187-0

28. Hanif R, Qiao L, Shiff SJ, Rigas B. Curcumin, a natural plant phenolic food additive, inhibits cell proliferation and induces cell cycle changes in colon adenocarcinoma cell lines by a prostaglandin-independent pathway. J Lab Clin Med 1997; 130: 576-84. http://dx.doi.org/10.1016/S0022-2143(97)90107-4

29. Dorai T, Cao YC, Dorai B, Buttyan R, Katz AE. Therapeutic potential of curcumin in human prostate cancer III. Curcumin inhibits proliferation, induces apoptosis, and inhibits angiogenesis of LNCaP prostate cancer cells in vivo. Prostate 2001; 47(4): 293 303. http://dx.doi.org/10.1002/pros.1074.abs

30. Nagpal Monika and Sood Shayeta. Role of curcumin in systemic and oral health: An overview. J Nat Sci Biol Med 2013; 4(1): 3-7. http://dx.doi.org/10.4103/0976-9668.107253

31. Ivan Ross A. Medical Plant of the World. Tatowa, New Jersey: Human Press Inc; 1999.

32. Sangeeta Singh, Subrata Roy, SK Chumber. Evaluation of two local drug delivery systems as adjuncts to mechanotherapy as compared to mechanotherapy alone in management of chronic periodontitis: A clinical, microbiological and molecular study. J Indian Soc Periodontol 2009; 13(3): 126-132. http://dx.doi.org/10.4103/0972124X.60224

33. Pandit Nymphea, Dahiya Ritu, Gupta Rajan, Bali Deepika and Kathuria Abhinav. Comparative evaluation of locally delivered minocycline and metronidazole in the treatment of periodontitis. Contemp Clin Dent 2013; 4(1): 48-53. http://dx.doi.org/10.4103 /0976-237X.111615

34. Nayyar Nandini, Dodwad Vidya, Arora Komal. Comparative evaluation of $1 \%$ curcumin solution and $0.2 \%$ chlorhexidine irrigation as an adjunct to scaling and root planning in management of chronic periodontitis: A clinic-microbiological study. Journal of Pharmaceutical and Biomedical Sciences 2012; 14(03)

35. Sidhu GS, Singh AK, Thaloor D, Banaudha KK, Patnaik GK, Srimal RC, Maheshwari RK. Enhancement of wound healing by curcumin in animals. Wound Repair and Regen 1998; 6(2): 167 177. http://dx.doi.org/10.1046/j.1524-475X.1998.60211.x

36. Gopinath D, Ahmed MR, Gomathi K, Chitra K, Sehgal PK, Jaykumar R. Dermal wound healing processes with curcumin incorporated collagen films. Biomaterials 2004; 25: 1911-1917. http://dx.doi.org/10.1016/S0142-9612(03)00625-2

Cite this article as:

Merline K. Varghese, Nagarathna D.V, Litty Scariya. Curcumin and metronidazole in periodontal therapy. Int. J. Res. Ayurveda Pharm. 2014;5(6):680-684 http://dx.doi.org/10.7897/2277-4343.056138 